\title{
The Basolateral Amygdala Is Critical for the Acquisition and Extinction of Associations between a Neutral Stimulus and a Learned Danger Signal But Not between Two Neutral Stimuli
}

\author{
Shauna L. Parkes and R. Frederick Westbrook \\ School of Psychology, University of New South Wales, Sydney, 2052 New South Wales, Australia
}

We studied the neural substrates of higher-order conditioned fear in rats. We first studied acquisition and extinction of second-order fear. One stimulus (S1) was paired with a footshock unconditioned stimulus (US), a second stimulus (S2) was paired with S1, and, finally, fear of S2 was extinguished by S2 alone exposures. Reversible inactivation of the basolateral amygdala (BLA) via muscimol, systemic injection of the NMDA receptor (NMDAr) antagonist MK-801 [(+)-5-methyl-10,11-dihydro-5H-dibenzo [a,d] cyclohepten-5,10-imine maleate], or intra-amygdala infusion of the NMDAr NR2B subunit selective antagonist ifenprodil impaired both acquisition and extinction of fear to S2. We then studied acquisition and extinction of sensory preconditioned fear. S2 was first paired with S1, S1 was then paired with the US, and, finally, fear of S2 was extinguished by S2 alone exposures. Extinction of sensory preconditioned fear was impaired by a BLA infusion of muscimol or ifenprodil and by MK-801. Acquisition of the S2-S1 association and extinction of this association by S2 alone exposures before conditioning of S1 was impaired by MK- 801 but not by a BLA infusion of muscimol. These results show that NMDAr activation in the BLA is critical for acquisition of second-order conditioned fear and for the extinction of both second-order and sensory preconditioned fear just as it is for acquisition and extinction of first-order conditioned fear. Acquisition and extinction of an association between two neutral stimuli also require NMDAr activation. However, the present results show that the acquisition and extinction of these associations do not require the BLA.

\section{Introduction}

Acquisition and extinction of fear responses in laboratory rodents are widely used to study the substrates of learning and memory in the mammalian brain. Acquisition occurs when rats are exposed to a signaling relation between an innocuous stimulus (e.g., tone) and an innate source of danger (e.g., shock). This relation produces an association between the tone [conditioned stimulus (CS)] and the shock unconditioned stimulus (US) that is expressed on subsequent presentations of the CS in behavioral and autonomic responses indicative of fear. Extinction occurs when rats are exposed to the CS in the absence of the US. Fear responses are inhibited across these exposures and eventually cease. The basolateral complex of the amygdala (BLA) (lateral, basolateral, and basomedial nuclei) is critical for acquisition and extinction of these first-order fear responses. For example, temporary inactivation of the BLA with the GABA agonist muscimol before conditioning impairs acquisition (Wilensky et al., 1999), whereas inactivation before extinction impairs long-term fear inhibition (Herry et al., 2008). NMDA receptor (NMDAr) activation in the BLA is necessary for the transduction cascade that mediates the plasticity underlying the formation of the fear and

\footnotetext{
Received June 10, 2010; revised July 20, 2010; accepted July 23, 2010.

This work was supported by grants from the Australian Research Council (Discovery) and National Health and Medical Research Council (R.F.W.) and by an Australian Postgraduate Award (S.L.P.).

Correspondence should be addressed to R. Fredrick Westbrook, School of Psychology, The University of New South Wales, Sydney, 2052 NSW, Australia. E-mail: fwestbrook@psy.unsw.edu.au.

DOI:10.1523/JNEUROSCI.2949-10.2010

Copyright $\odot 2010$ the authors $\quad$ 0270-6474/10/3012608-11\$15.00/0
}

inhibitory memories. Preconditioning lateral amygdala infusion of ifenprodil, an NMDAr antagonist that selectively blocks the NR2B subunit, impairs acquisition (Rodrigues et al., 2001), whereas preextinction infusion impairs long-term fear inhibition (Sotres-Bayon et al., 2007).

Rats learn to fear not only stimuli (tone) that signal innate sources of danger (aversive US) but also other stimuli (e.g., light) that signal a learned source of danger (tone). "Higher-order" fear has been observed in two procedures. In second-order conditioning, pairings of a tone and shock are followed by pairings of a light and the tone; in sensory preconditioning, pairings of a light and tone are followed by pairings of the tone and shock. In each procedure, test presentations of the light alone elicit fear responses that are extinguished across such presentations. Both of these higher-order fears are well documented (Gewirtz and Davis, 2000), but their neural substrates have received little investigation. There is evidence that the BLA is involved in acquisition (Nader and LeDoux, 1999) and reconsolidation (Debiec et al., 2006) of second-order fear. Moreover, acquisition of secondorder fear was disrupted by infusion of the NMDAr antagonist DL-APV into the BLA (Gewirtz and Davis, 1997). However, DLAPV disrupts basal synaptic transmission in the amygdala (Bauer et al., 2002). Therefore, the impairment may have been attributable to disruption of neuronal activity rather than antagonism of NMDAr-mediated plasticity in the BLA. There has been no investigation of the roles of the BLA and NMDAr activation in acquisition of sensory preconditioned fear or in extinction of either this or second-order fear. 
We examined whether the substrates identified here that mediate acquisition and extinction of first-order fear also mediate acquisition and extinction of second-order and sensory preconditioned fear by (1) reversible inactivation of the BLA via muscimol, (2) systemic administration of the NMDAr antagonist MK-801 [(+)-5-methyl-10,11-dihydro-5H-dibenzo [a,d] cyclohepten-5,10-imine maleate], and (3) BLA infusion of ifenprodil.

\section{Materials and Methods}

Subjects. Subjects were experimentally naive male outbred Wistar rats (280-350 g) obtained from a commercial supplier (Animal Resources Centre). After arrival, they were housed in groups of eight in plastic boxes. Rats were maintained in a climate-controlled colony room (lights on at 7:00 A.M.). Food and water was available ad libitum. All experimental procedures were approved by the Animal Care and Ethics Committee at the University of New South Wales and in accordance with the National Institutes of Health Guide for the Care and Use of Laboratory Animals, revised 1996.

Surgery and drug infusions. Before behavioral testing, rats were implanted with guide cannula directed toward the BLA. Rats were injected intraperitoneally with $1.3 \mathrm{ml} / \mathrm{kg}$ of the anesthetic ketamine (Ketapex; Apex Laboratories) at a concentration of $100 \mathrm{mg} / \mathrm{ml}$ and $0.3 \mathrm{ml} / \mathrm{kg}$ of the muscle relaxant xylazine (Rompun; Bayer) at a concentration of $20 \mathrm{mg} /$ $\mathrm{ml}$. Anesthetized rats were then mounted on a stereotaxic apparatus (David Kopf Instruments), and 26 gauge guide cannula (Plastics One) were implanted through holes drilled in both hemispheres of the skull. The tips of the guide cannula were aimed bilaterally at the BLA using the following coordinates: anteroposterior, $-2.3 \mathrm{~mm}$; mediolateral, $\pm 4.9-5$ $\mathrm{mm}$; dorsoventral, 7.7-7.9 $\mathrm{mm}$. All coordinates given are distance from bregma according to the rat brain atlas of Paxinos and Watson (1997). The guide cannulas were maintained in position with dental cement, and dummy cannulas were kept in each guide at all times except during microinfusions. Immediately after the surgical procedure, rats were injected intraperitoneally with a prophylactic $(0.4 \mathrm{ml})$ dose of $300 \mathrm{mg} / \mathrm{kg}$ solution of procaine penicillin. Rats were allowed $4 \mathrm{~d}$ to recover from surgery, during which time they were handled and weighed daily.

Muscimol, ifenprodil, or vehicle was infused bilaterally in the BLA by inserting a 33 gauge internal cannula into the guide cannula. The internal cannula was connected to a $25 \mu$ l glass syringe attached to an infusion pump (Harvard Apparatus) and projected an additional $1 \mathrm{~mm}$ ventral to the tip of the guide cannula. A total volume of $0.3 \mu \mathrm{l}$ was delivered to both sides at a rate of $0.1 \mu \mathrm{l} / \mathrm{min}$. The internal cannula remained in place for an additional $1 \mathrm{~min}$ after the infusions and was then removed. One day before infusions, the dummy cannula was removed, and the infusion pump was turned on for $3 \mathrm{~min}$ to familiarize the rats with the procedure and thereby minimize stress.

Drugs. The noncompetitive NMDA receptor antagonist MK-801 (Sigma) was dissolved in $0.9 \%(\mathrm{w} / \mathrm{v})$ nonpyrogenic saline and injected intraperitoneally in a volume of $1.0 \mathrm{ml} / \mathrm{kg}$. The concentration of the drug in saline $(\mathrm{w} / \mathrm{v})$ was adjusted to obtain a dosage of $0.1 \mathrm{mg} / \mathrm{kg}$. Saline was used for vehicle injections in experiments using MK-801. The GABA agonist muscimol (Sigma) was dissolved in nonpyrogenic saline $(0.9 \%$ $\mathrm{w} / \mathrm{v})$ to obtain a final concentration of $0.3 \mu \mathrm{g} / 0.3 \mu \mathrm{l}$. Nonpyrogenic saline was used as a vehicle for experiments studying the effects of muscimol. Ifenprodil, a selective antagonist that blocks the NR2B subunit of NMDAr (Sigma), was dissolved in a solution of $0.9 \%$ nonpyrogenic saline (w/v) containing $5 \%$ of (2-hydrocypropryl)- $\beta$-cyclodextrin (Sigma) adjusted to $\mathrm{pH}$ 7. This latter solution was used as a vehicle for experiments studying the effects of ifenprodil. Ifenprodil was microinjected into the BLA at a final concentration of $1 \mu \mathrm{g} / 0.3 \mu \mathrm{l}$. The interval between drug administration and behavior was 30, 20, and 15 min for MK-801, muscimol, and ifenprodil, respectively. These intervals were selected on the basis of results from pilot studies in this laboratory.

Histology. Subsequent to behavioral testing, subjects received a lethal dose of sodium pentobarbital. The brains were removed and sectioned coronally at $40 \mu \mathrm{m}$ through the BLA. Every third section was collected on a slide and stained with cresyl violet. The location of cannula tips was determined under a microscope by a trained observer, unaware of the subjects' group designations, using the boundaries defined by the atlas of Paxinos and Watson (1997). Subjects with inaccurate cannula placements or with extensive damage to the BLA were excluded from the statistical analysis.

Behavioral apparatus. For all experiments, training, extinction, and testing were conducted in a set of eight chambers. The sidewalls and ceiling of each chamber $(30 \mathrm{~cm}$ height $\times 27 \mathrm{~cm}$ length $\times 30 \mathrm{~cm}$ width) were made of aluminum, and the back and front walls were made of clear plastic. The sidewalls and ceiling were painted black. The floor consisted of stainless steel rods, $2 \mathrm{~mm}$ in diameter, spaced $13 \mathrm{~mm}$ apart, center to center. A tray below the floor contained bedding material. Each chamber was enclosed in a sound- and light-attenuating shell. A white fluorescent tube and a speaker mounted on the back wall of each shell were used, respectively, for the presentation of a light CS ( $\sim 57$ lux measured at the center of the chamber) flashing at a rate of $3 / \mathrm{s}$ and a $620 \mathrm{~Hz}$ square-wave tone CS measuring $70 \mathrm{~dB}$ (A scale) against a background noise of $\sim 45 \mathrm{~dB}$ measured by a digital sound level meter (Dick Smith Electronics). The physical identity of all CSs was fully counterbalanced. The levels of responding to the CSs did not differ as a function of their physical identity in any experiment.

A custom-built constant-current shock generator, capable of delivering unscrambled alternating current $50 \mathrm{~Hz}$ shock to the floor of each chamber, was used for the presentation of a 0.5 -s-duration shock at 0.8 $\mathrm{mA}$ intensity. The floor of each chamber was cleaned with $1 \%$ acetic acid after removal of each rat. Illumination for each chamber was provided by an infrared light source $(940 \pm 25 \mathrm{~nm})$. A camera mounted on the back wall of each shell recorded the behavior of each rat. Each camera was connected to a monitor and a DVD recorder located in another room of the laboratory. This room contained the computer that controlled stimulus presentations via appropriate software (LabView; National Instruments).

Preexposure. On the first $2 \mathrm{~d}$, rats received two 29 min exposures per day to the conditioning chambers. For experiments involving secondorder conditioning only, rats also received two 29 min stimulus preexposure sessions on day 3. In each stimulus preexposure session, rats were placed into the context and the first stimulus was presented after a $3 \mathrm{~min}$ adaptation period. Each of the two stimuli was presented four times in an intermixed, pseudorandom order, except that no one stimulus was presented more than two times consecutively. The duration of each stimulus was 30 and $10 \mathrm{~s}$ intermixed presentations. The interval between each stimulus presentation, defined as stimulus offset to stimulus onset, was 3 min. After the final stimulus presentation, rats remained in the context for an additional $2 \mathrm{~min}$ before they were returned to their home cages.

First-order conditioning. Each first-order conditioning session consisted of two presentations each of S1 (10 s) and the US ( $0.5 \mathrm{~s}, 0.8 \mathrm{~mA}$ footshock). Rats were placed into the conditioning context, and, after a 5 min adaptation period, $\mathrm{S} 1$ was presented. For rats receiving paired firstorder conditioning, S1 and the US coterminated, whereas S1 and the US were explicitly unpaired in groups receiving unpaired first-order conditioning. The average intertrial interval (ITI) between paired S1-US presentations was $12 \mathrm{~min}$ and $10 \mathrm{~min}$ for unpaired presentations. Rats remained in the conditioning chamber for a minimum of $1 \mathrm{~min}$ after the final stimulus presentation.

Second-order conditioning. Twenty-four hours before second-order conditioning, rats received two context extinction sessions. In each session, rats were placed in the conditioning chamber for $29 \mathrm{~min}$ and were then returned to their home boxes. No stimuli were presented in this phase. The context was extinguished to allow a clearer assessment of the acquisition of freezing to $S 2$ across its pairings with $S 1$ and to minimize any generalization of fear from the context to $\mathrm{S} 2$ in control rats that received unpaired presentations of $S 1$ and the US. Second-order conditioning consisted of four presentations each of S2 and S1. Rats were placed in the conditioning context, and, after a $5 \mathrm{~min}$ adaptation period, S2 was presented. For groups receiving paired second-order conditioning, S2 and S1 were paired such that the offset of S2 immediately preceded the onset of S1. The ITI for paired presentations was $5 \mathrm{~min}$. S2 and $S 1$ were unpaired for groups receiving unpaired second-order conditioning (average ITI, $6 \mathrm{~min}$ ). Rats remained in the conditioning chamber for 


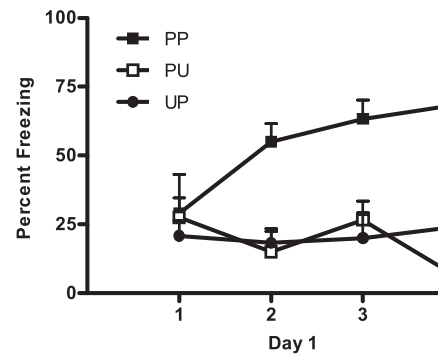

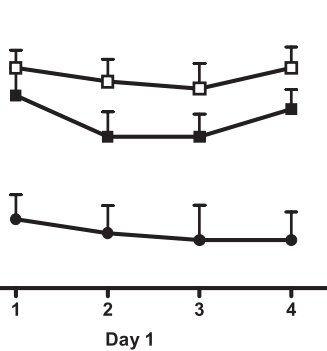

s2

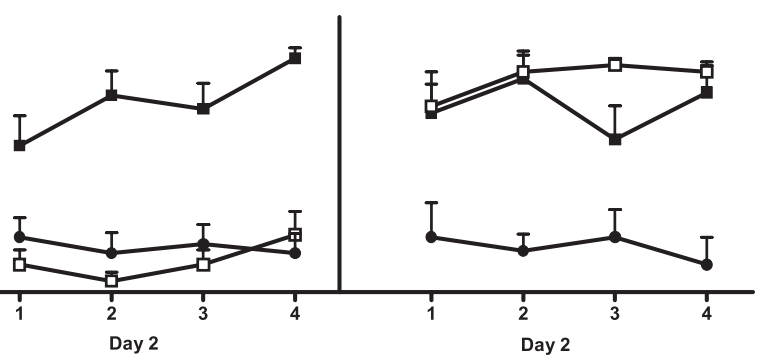

Figure 1. Behavioral demonstration of second-order conditioning (experiment 1). Mean + SEM levels of freezing to S2 and S1 across day 1 of second-order conditioning (left panels) and to S2 and S1 across day 2 of second-order conditioning (right panels) for groups PP (filled squares), PU (open squares), and UP (filled circles).

a minimum of $1 \mathrm{~min}$ after the final stimulus presentation. Rats in experiment 1 received $2 \mathrm{~d}$ of second-order conditioning, whereas rats in experiments 2 and 3 received $1 \mathrm{~d}$ of second-order conditioning.

Second-order extinction. Rats were placed into the conditioning context, and, after 5 min adaptation period, S2 was presented. S2 was presented eight times with an ITI of 3 min, yielding a 30 min extinction session.

Sensory preconditioning. Sensory preconditioning consisted of eight presentations each of S2 and S1 in a $1 \mathrm{~h}$ session. Rats were placed in the chamber, and, after a 5 min adaptation period, S2 was presented. For groups receiving paired sensory preconditioning, the offset of S2 immediately preceded the onset of S1, whereas $S 2$ and S1 were explicitly unpaired for groups receiving unpaired sensory preconditioning. The ITI was 6 and $3 \mathrm{~min}$ for paired and unpaired presentations, respectively. Rats remained in the conditioning chamber for a minimum of $1 \mathrm{~min}$ after the final stimulus presentation.

Sensory preconditioning extinction. Rats were placed into the conditioning context, and, after a 5 min adaptation period, S2 was presented. S2 was presented eight times with an ITI of $3 \mathrm{~min}$, yielding a $30 \mathrm{~min}$ extinction session.

Testing. Rats received one S2 test session and one S1 test session on separate, consecutive days. Rats were placed into the conditioning context, and, after a 5 min adaptation period, the stimulus was presented. Each test session consisted of eight stimulus presentations with an ITI of 3 min, yielding 30 min test sessions.

Data analysis. Freezing was used to assess conditioned fear. It was defined as the absence of all movement except those related to breathing (Fanselow, 1980). Each rat was observed every $2 \mathrm{~s}$ and scored as either "freezing" or "not freezing" by two observers, one of whom was naive to group allocation. A percentage score was calculated for the proportion of the total observation each rat spent freezing. There was a high degree of agreement between the two observers, with a Pearson's product moment correlation $>0.90$. Data were analyzed by means of a planned, orthogonal contrast procedure controlling the per-contrast error rate (Hays, 1963). Significance was set at $\alpha=0.05$.

\section{Results}

Experiment 1: Acquisition of second-order fear responses to $S 2$ is contingent on its pairings with $S 1$ and on previous pairings of $S 1$ and the US

The aim of this experiment was to confirm that second-order fear to S2 was contingent on its pairings with $\mathrm{S} 1$ and on previous pairings of S1 and the US. Three groups of rats were used $(n=8)$. Each group is labeled according to its treatment in first- and second-order conditioning, respectively. A "P" indicates a paired presentation and " $U$ " indicates an unpaired presentation. On the first $3 \mathrm{~d}$, all groups received preexposure to the conditioning context and stimuli. On days 4-5, rats received paired (groups PP and PU) or unpaired first-order conditioning (group UP). On day 6 , all groups were extinguished to the context. On days 7-8, rats received paired (groups PP and UP) or unpaired (group PU) second-order conditioning.

\section{Behavior}

Levels of freezing during the $30 \mathrm{~s}$ before the first stimulus onset were $<20 \%$ across all phases of the experiment and did not differ significantly between groups $\left(F_{(1,21)}<1 ; p>0.05\right)$. First-order conditioning was successful. Levels of freezing to $S 1$ were significantly higher for groups receiving paired first-order conditioning (groups PP and PU) than for the group receiving unpaired conditioning (group UP; $F_{(1,21)}=6.07 ; p<0.05$ ). Levels of freezing did not differ between groups $\mathrm{PP}$ and $\mathrm{PU}\left(F_{(1,21)}<1 ; p>\right.$ $0.05)$. Figure 1 shows mean + SEM levels of freezing to S2 and S1 on day 1 (left panels) and day 2 (right panels) of second-order conditioning. Development of conditioned fear responses to S2 occurred in group PP only. No differences in levels of freezing to S2 were found between group PP and the unpaired groups on the initial trial of second-order training $\left(F_{(1,21)}<1\right.$; $\left.p>0.05\right)$, however, across the $2 \mathrm{~d}$ of second-order training, group PP demonstrated significantly higher levels of freezing to S2 than the unpaired groups $\left(F_{(1,21)}=63.71 ; p<0.05\right)$. A significant linear $\times$ group interaction confirmed the rate of acquisition of secondorder fear was greater for group PP than for the unpaired groups $\left(F_{(1,21)}=34.37 ; p<0.05\right)$. Levels of freezing to S2 did not differ between unpaired groups $\left(F_{(1,21)}<1 ; p>0.05\right)$. Rats that had received paired first-order conditioning froze more to $S 1$ than rats that had received unpaired first-order conditioning $\left(F_{(1,21)}=\right.$ $42.5 ; p<0.05)$. Rats in groups PP and PU did not differ significantly $\left(F_{(1,21)}<3.8 ; p>0.05\right)$. Thus, the ability of $\mathrm{S} 1$ to produce second-order conditioned fear was contingent on its association with the US, and the ability of S2 to acquire fear was contingent on its association with $\mathrm{S} 1$.

\section{Experiment 2: Acquisition of second-order conditioned fear requires the $B L A, N M D A r$ activation, and NR2B subunit activation in the BLA}

In this experiment, rats received pairings of S2 and S1 under a BLA infusion of the $\mathrm{GABA}_{\mathrm{A}}$ receptor agonist muscimol (group MUS), systemic administration of the NMDAr antagonist MK801 (group MK-801), or a BLA infusion of the NMDAr NR2B subunit selective antagonist ifenprodil (group IFEN). All groups received paired first- and second-order conditioning. These experiments were run consecutively. On the first $3 \mathrm{~d}$, rats were preexposed to the conditioning context and stimuli. On days $4-5$, all rats received paired first-order conditioning and on day 6 received context extinction. On day 7 , half of the rats were injected/infused with drug, whereas the remaining rats received the appropriate control injection/infusion. Then, all rats received pairings of S2 and S1. They were tested for fear of S2 and S1 on days 8 and 9 , respectively. 
A
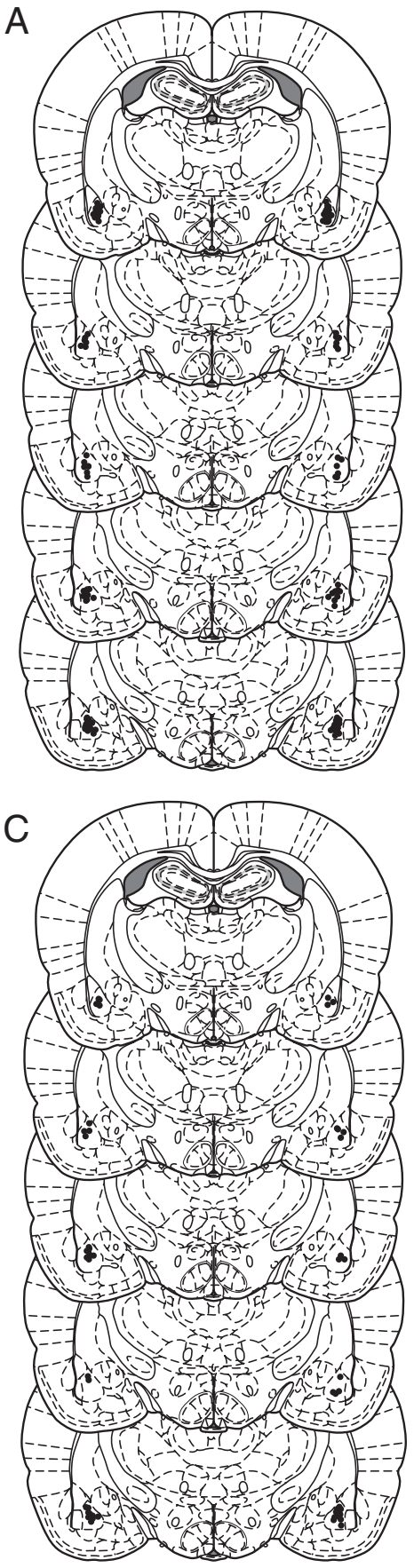

$\mathrm{B}$

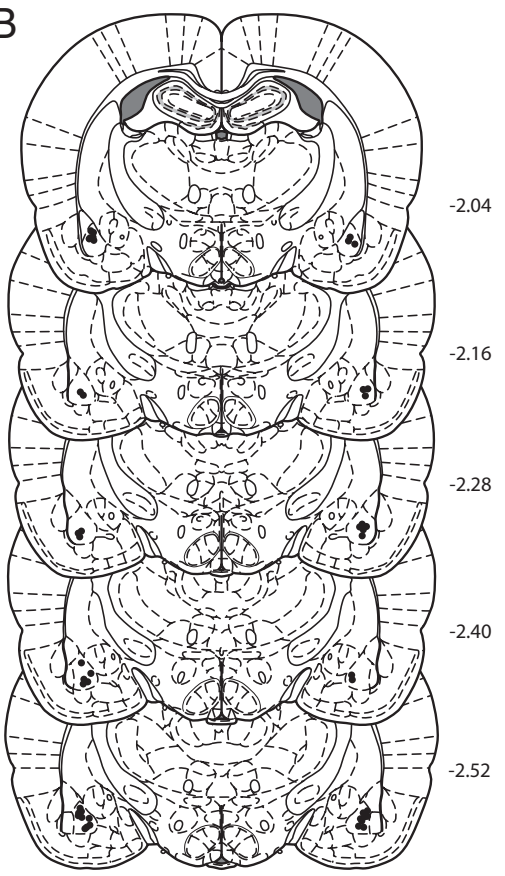

$\mathrm{D}$

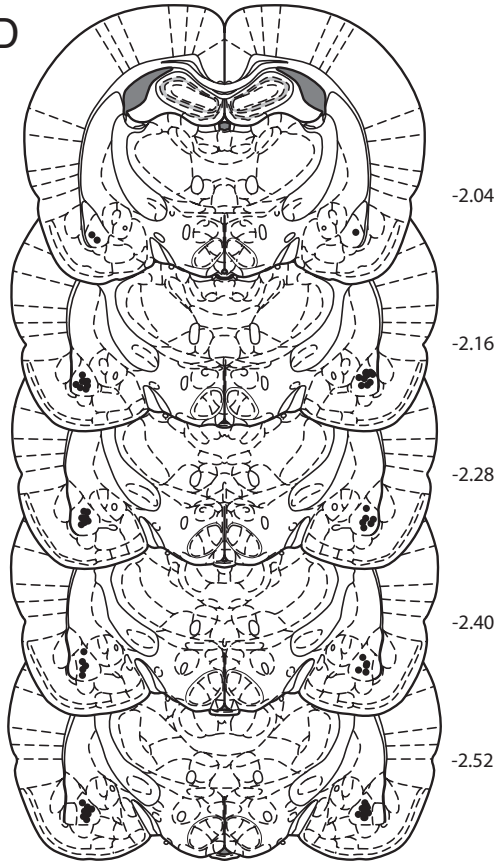

Figure 2. Microinfusion cannula placements as verified on Nissl-stained section for experiment $2(\boldsymbol{A})$, experiment $3(\boldsymbol{B})$, experiment 5 (C), and experiments 6 and 7 (D). The symbols represent the most ventral point of the cannula track for each rat on coronal sections based on the atlas of Paxinos and Watson (1997).

\section{Histology}

Figure $2 \mathrm{~A}$ shows the approximate location of injection cannula tips. The plotted points represent the ventral point of the cannula track. Two rats were excluded yielding the following group sizes for each experiment: group MUS, $n=8$; group VEH (muscimol control), $n=8$; group $\mathrm{MK}-801, n=8$; group $\mathrm{VEH}$ (MK-801 control), $n=8$; group IFEN, $n=13$; and group VEH (ifenprodil control), $n=13$.

\section{Behavior}

$B L A$ infusion of $G A B A_{A}$ receptor agonist muscimol. Levels of freezing during the $30 \mathrm{~s}$ period before the first stimulus onset were
$<20 \%$ across all phases of the experiment and did not differ significantly between groups $\left(F_{(1,14)}<1 ; p>0.05\right)$. First-order conditioning was successful. No significant difference in freezing to $S 1$ was found between groups across first-order training $\left(F_{(1,14)}<1 ; p>0.05\right)$. A nonsignificant linear $\times$ group interaction confirmed the rate of acquisition of fear to $\mathrm{S} 1$ did not differ between groups $\left(F_{(1,14)}<2.2 ; p>\right.$ $0.05)$. Figure $3 A$ shows the mean + SEM levels of freezing to S2 (left panel) and S1 (middle panel) across second-order conditioning. Muscimol depressed the freezing response. Group VEH froze significantly more to S2 than group MUS $\left(F_{(1,14)}=39.94 ; p<0.05\right)$. A significant linear $\times$ group interaction confirmed the rate of acquisition was greater for group VEH than group MUS $\left(F_{(1,14)}=16.62\right.$; $p<0.05$ ). Group VEH also froze significantly more to $\mathrm{S} 1$ than group MUS $\left(F_{(1,14)}=89.82 ; p<0.05\right)$. The right panel of Figure $3 A$ shows the mean + SEM levels of freezing to S2 across testing. BLA activation is necessary for the acquisition of second-order conditioned fear. Group VEH froze significantly more to S2 than group $\operatorname{MUS}\left(F_{(1,14)}=11.50 ; p<\right.$ $0.05)$. A significant linear $\times$ group interaction confirmed the decline in freezing was greater for vehicle than muscimol rats $\left(F_{(1,14)}=19.50 ; p<0.05\right)$. Muscimol infused before second-order conditioning left the first-order fear memory intact. Levels of freezing to $\mathrm{S} 1$ at test did not differ between groups $\left(F_{(1,14)}<1\right.$; $p>$ $0.05)$. This was confirmed by a nonsignificant linear $\times$ group interaction $\left(F_{(1,14)}<\right.$ $2.3 ; p>0.05)$.

Systemic administration of the NMDAr antagonist MK-801. Levels of freezing during the $30 \mathrm{~s}$ period before the first stimulus onset were $<20 \%$ across all phases of the experiment and did not differ significantly between groups $\left(F_{(1,14)}<1 ; p>0.05\right)$. First-order conditioning was successful. No significant difference in freezing was found between groups across first-order training $\left(F_{(1,14)}<1 ; p>0.05\right)$. A nonsignificant linear $\times$ group interaction confirmed that the rate of acquisition of fear to S1 did not differ between groups $\left(F_{(1,14)}<1 ; p>0.05\right)$. Figure $3 B$ shows mean + SEM levels of freezing to S2 (right panel) and S1 (middle panel) across second-order conditioning. MK-801 depressed the freezing response. Vehicle-treated rats froze more to S2 than MK-801-treated rats $\left(F_{(1,14)}=22.83 ; p<\right.$ $0.05)$. A significant linear $\times$ group interaction confirmed that the rate of acquisition of second-order fear was greater for group $\mathrm{VEH}$ than group MK-801 $\left(F_{(1,14)}=30.21 ; p<0.05\right)$. Vehicletreated rats also froze more to $\mathrm{S} 1$ than $\mathrm{MK}-801$-treated rats $\left(F_{(1,14)}=15.68 ; p<0.05\right)$. The right panel of Figure $3 B$ shows the mean + SEM levels of freezing to S2 across testing. NMDAr 

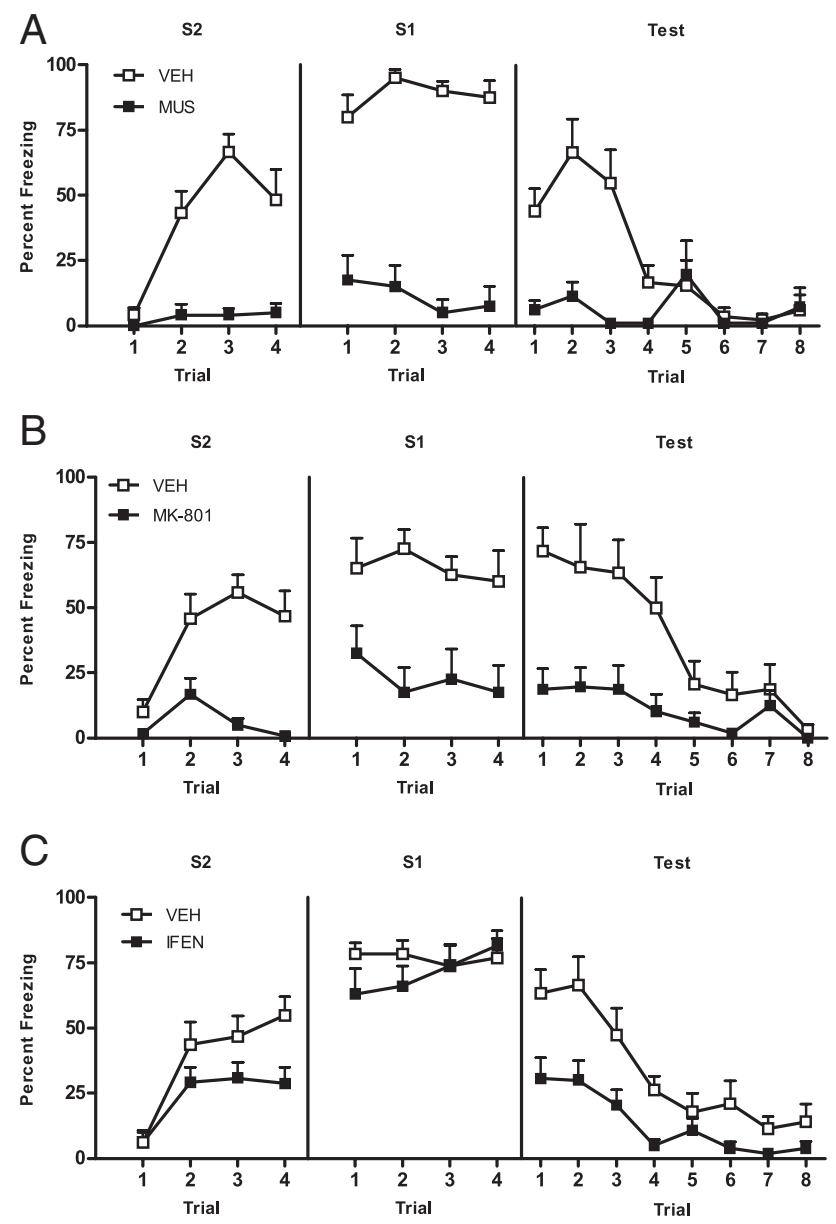

Figure 3. Acquisition of second-order fear requires the BLA, NMDAr, and NR2Br activation in the BLA (experiment 2). Drug-treated rats are shown with filled squares, and vehicle-treated rats are shown with open squares. Mean + SEM levels of freezing to S2 and S1 across secondorder conditioning (left and middle panels) and at $\mathbf{S 2}$ test (right panel) for muscimol- and vehicle-treated rats $(\boldsymbol{A})$, MK-801- and vehicle-treated rats $(\boldsymbol{B})$, ifenprodil- and vehicle-treated rats $(\boldsymbol{C})$.

activation is necessary for the acquisition of second-order conditioned fear. Vehicle-treated rats froze more to S2 than MK-801treated rats $\left(F_{(1,14)}=18.12 ; p<0.05\right)$. A significant linear $\times$ group interaction confirmed the decline in freezing was greater for group VEH than group MK-801 $\left(F_{(1,24)}=11.87 ; p<0.05\right)$. Injection of MK-801 before second-order conditioning did not affect the long term first-order fear memory. Levels of freezing to $S 1$ at test did not differ between groups $\left(F_{(1,14)}<1 ; p>0.05\right)$. This was confirmed by a nonsignificant linear $X$ group interaction $\left(F_{(1,14)}<1 ; p>0.05\right)$.

$B L A$ infusion of the NMDAr NR2B subunit-selective antagonist ifenprodil. Levels of freezing during the 30 s period before the first stimulus onset were $<15 \%$ across all phases of the experiment and did not differ significantly between groups $\left(F_{(1,24)}<1 ; p>\right.$ $0.05)$. First-order conditioning was successful. No significant difference in freezing was found between groups across first-order training $\left(F_{(1,24)}<1 ; p>0.05\right)$. A nonsignificant linear $\times$ group interaction confirmed that the rate of acquisition of fear to S1 did not differ between groups $\left(F_{(1,24)}<1 ; p>0.05\right)$. Figure $3 C$ shows the mean + SEM levels of freezing to S2 (left panel) and S1 (middle panel) across second-order conditioning. Ifenprodil impaired the acquisition of second-order conditioned fear. Vehicle-treated rats froze more to $\mathrm{S} 2$ across training than ifenprodil-treated rats
$\left(F_{(1,24)}=4.42 ; p<0.05\right)$. Ifenprodil did not depress the freezing response. No significant difference in levels of freezing to S1 was found between vehicle- and ifenprodil-treated rats across second-order conditioning $\left(F_{(1,24)}<1 ; p>0.05\right)$. The right panel of Figure $3 C$ shows the mean + SEM levels of freezing to $S 2$ across testing. Activation of NMDA NR2B subunit receptors in the BLA is necessary for the acquisition of second-order conditioned fear. Vehicle-treated rats froze more to S2 than ifenprodil-treated rats $\left(F_{(1,24)}=11.00 ; p<0.05\right)$. A significant linear $\times$ group interaction confirmed that the decline in freezing to $\mathrm{S} 2$ was greater for group VEH than group IFEN $\left(F_{(1,24)}=5.86 ; p<0.05\right)$. Infusion of ifenprodil before second-order conditioning did not affect the long term first-order fear memory. Levels of freezing to S1 at test did not differ between groups $\left(F_{(1,24)}<1\right.$; $\left.p>0.05\right)$. This was confirmed by a nonsignificant linear $\times$ group interaction $\left(F_{(1,24)}<1 ; p>0.05\right)$.

\section{Experiment 3: Extinction of second-order conditioned fear requires the BLA, NMDAr activation, and NR2B subunit activation in the BLA}

In this experiment, we studied the effect of BLA infusion of the $\mathrm{GABA}_{\mathrm{A}}$ receptor agonist muscimol (group MUS), systemic administration of the NMDAr antagonist MK-801 (group MK801), and BLA infusion of the NMDAr NR2B subunit-selective antagonist ifenprodil (group IFEN) on the extinction of secondorder conditioned fear. These experiments were run consecutively. On the first $3 \mathrm{~d}$, rats were preexposed to the conditioning context and stimuli. On days $4-5$, all rats received paired firstorder conditioning and on day 6 received context extinction. On day 7 , all rats received paired second-order conditioning. On day 8 , rats were infused/injected with drug or vehicle and then received S2 extinction training. All rats were tested for fear of S2 and $\mathrm{S} 1$ on days 9 and 10, respectively.

\section{Histology}

Figure $2 B$ shows the approximate location of injection cannula tips. The plotted points represent the ventral point of the cannula track. Six rats were excluded because of damage. This yielded the following group sizes: group MUS, $n=7$; group VEH (muscimol control), $n=8$; group MK-801, $n=11$; group VEH (MK-801 control), $n=10$; group IFEN, $n=14$; and group VEH (ifenprodil control), $n=15$.

\section{Behavior}

$B L A$ infusion of $G A B A_{A}$ receptor agonist muscimol. Levels of freezing during the $30 \mathrm{~s}$ period before the first stimulus onset were $<20 \%$ across all phases of the experiment and did not differ significantly between groups $\left(F_{(1,13)}<1 ; p>0.05\right)$. First-order conditioning was successful. No significant difference in freezing to $S 1$ was found between groups across first-order training $\left(F_{(1,13)}<\right.$ $1 ; p>0.05)$. A nonsignificant linear $\times$ group interaction confirmed that the rate of acquisition of fear to S1 did not differ between groups $\left(F_{(1,13)}<1 ; p>0.05\right)$. Figure $4 A$ shows the mean + SEM levels of freezing to S2 and S1 (left panels) across second-order conditioning. No significant difference in freezing to $\mathrm{S} 2$ or $\mathrm{S} 1$ was found between groups $\left(F_{(1,13)}<2.5 ; p>0.05\right)$. A nonsignificant linear $\times$ group interaction confirmed that the rate of acquisition of fear to S2 did not differ between groups $\left(F_{(1,13)}\right.$ $<1 ; p>0.05$ ). Figure $4 A$ (third panel) shows the mean + SEM levels of freezing across S2 extinction. Muscimol depressed the freezing response. Muscimol-treated rats froze less to S2 than vehicle rats $\left(F_{(1,13)}=21.17 ; p<0.05\right)$. A significant linear $\times$ group interaction confirmed that the rate of extinction was 
A

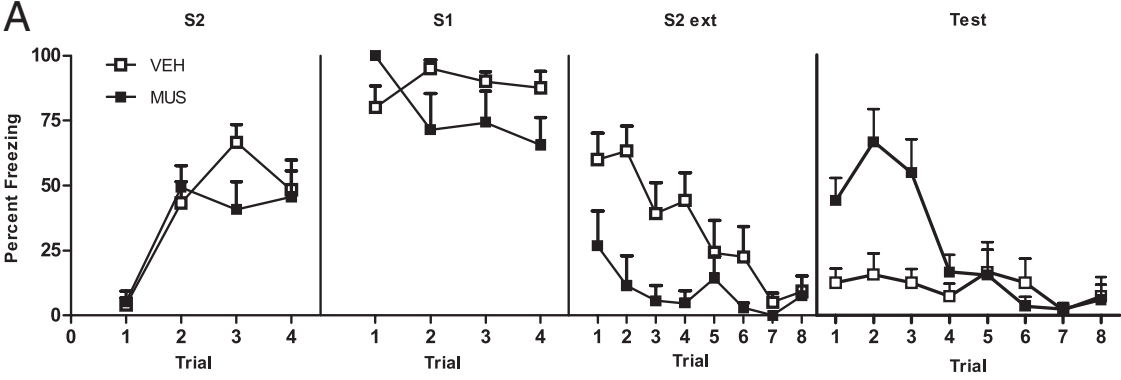

B

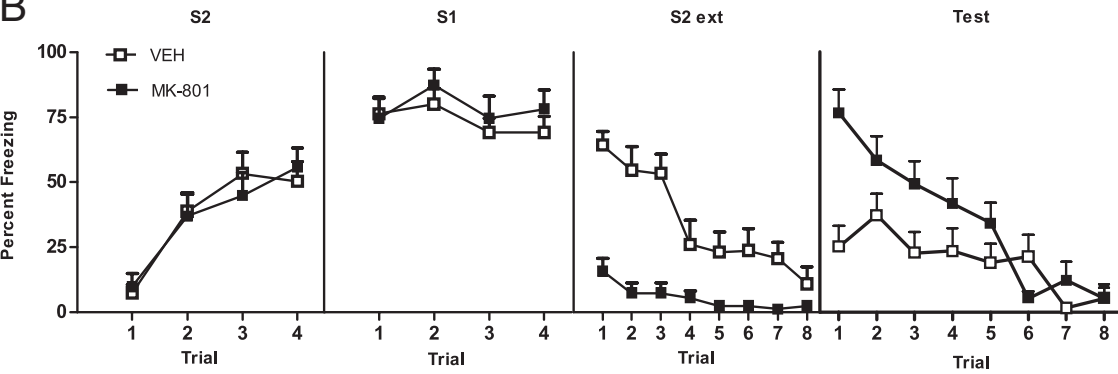

C

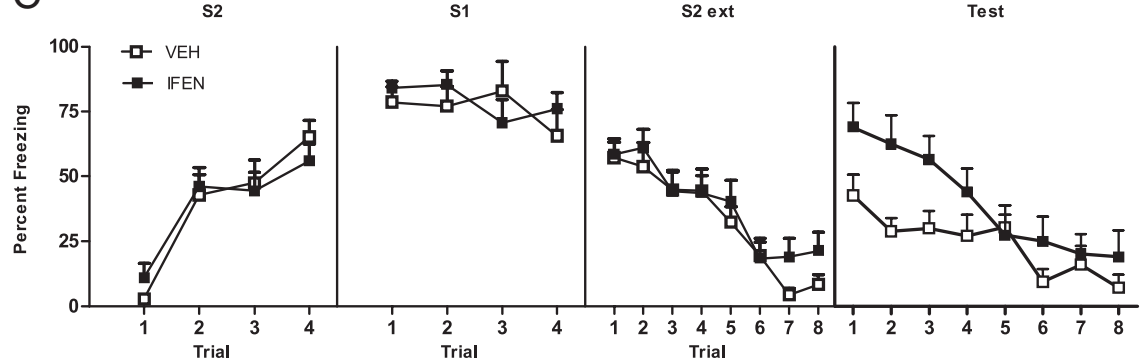

Figure 4. Extinction of second-order conditioned fear requires the BLA, NMDAr, and NR2Br activation in the BLA (experiment 3). Mean + SEM levels of freezing to S2 and S1 across second-order conditioning (left panels) and to S2 across extinction training and to $S 2$ at test (right panels) for muscimol- and vehicle-treated rats $(\boldsymbol{A})$, MK-801- and vehicle-treated rats $(\boldsymbol{B})$, and ifenprodil- and vehicle-treated rats $(\boldsymbol{C})$. Drug-treated rats are shown with filled squares, and vehicle-treated rats are shown with open squares.

greater in group VEH than in group $\operatorname{MUS}\left(F_{(1,13)}=10.9 ; p<\right.$ $0.05)$. The right panel of Figure $4 A$ shows the mean + SEM levels of freezing to S2 across testing. BLA activation is necessary for the extinction of second-order conditioned fear responses. Muscimol-treated rats showed significantly greater levels of freezing to $\mathrm{S} 2$ at test than vehicle rats $\left(F_{(1,13)}=11.5 ; p<0.05\right)$. A significant linear $\times$ group interaction confirmed that the decline in freezing to S2 was greater for group MUS than group VEH $\left(F_{(1,13)}=19.5 ; p<0.05\right)$. Inactivation of the BLA across S2 extinction training spared the first-order fear memory. Levels of freezing to $\mathrm{S} 1$ at test did not differ between groups $\left(F_{(1,13)}<1\right.$; $p>0.05)$. This was confirmed by a nonsignificant linear $\times$ group interaction $\left(F_{(1,13)}<1 ; p>0.05\right)$.

Systemic administration of NMDAr antagonist MK-801. Levels of freezing during the $30 \mathrm{~s}$ period before the first stimulus onset were $<20 \%$ across all phases of the experiment and did not differ significantly between groups $\left(F_{(1,19)}<1 ; p>0.05\right)$. First-order conditioning was successful. No significant difference in freezing to $\mathrm{S} 1$ was found between groups across first-order training $\left(F_{(1,19)}<1 ; p>0.05\right)$. A nonsignificant linear $\times$ group interaction confirmed that the rate of acquisition of fear to $S 1$ did not differ between groups $\left(F_{(1,19)}<2.2 ; p>0.05\right)$. Figure $4 B$ shows the mean + SEM levels of freezing to S2 and S1 (left panels) across second-order conditioning. No significant difference in freezing to S2 or S1 was found between groups across second-order conditioning $\left(F_{(1,19)}<1.3 ; p>0.05\right)$. A nonsignificant linear $\times$ group interaction confirmed that the rate of acquisition of fear to S2 did not differ between groups $\left(F_{(1,19)}<1 ; p>0.05\right)$. Figure $4 B$ (third panel) shows mean + SEM levels of freezing to S2 across extinction. MK-801 depressed the freezing response. MK-801treated rats froze less to $\mathrm{S} 2$ than vehicle rats $\left(F_{(1,19)}=39.19 ; p<0.05\right)$. A significant linear $\times$ group interaction confirmed that the rate of extinction was greater for group $\mathrm{VEH}$ than group $\mathrm{MK}$ $801\left(F_{(1,19)}=26.8 ; p<0.05\right)$. The right panel of Figure $4 B$ shows mean + SEM levels of freezing to S2 across testing. NMDAr activation is necessary for the extinction of second-order conditioned fear. Vehicle-treated rats showed less freezing to $\mathrm{S} 2$ than $\mathrm{MK}-801$ rats $\left(F_{(1,19)}=\right.$ 5.46; $p<0.05)$. A significant linear $X$ group interaction confirmed that the decline in freezing to S2 was greater for group MK-801 than group $\operatorname{VEH}\left(F_{(1,19)}=\right.$ 15.37; $p<0.05)$. Injection of MK-801 across S2 extinction did not affect the first-order fear memory. Levels of freezing to $\mathrm{S} 1$ at test did not differ between groups $\left(F_{(1,19)}<1 ; p>0.05\right)$. This was confirmed by a nonsignificant linear $\times$ group interaction $\left(F_{(1,19)}<1 ; p>0.05\right)$.

$B L A$ infusion of the NMDAr NR2B subunit-selective antagonist ifenprodil. Levels of freezing during the $30 \mathrm{~s}$ period before the first stimulus onset $<20 \%$ across all phases of the experiment and did not differ significantly between groups $\left(F_{(1,27)}<1 ; p>0.05\right)$. First-order conditioning was successful. No significant difference in freezing to $S 1$ was found between groups across first-order training $\left(F_{(1,27)}<1 ; p>0.05\right)$. A nonsignificant linear $\times$ group interaction confirmed that the rate of acquisition of fear to S1 did not differ between groups $\left(F_{(1,27)}\right.$ $<1 ; p>0.05)$. Figure $4 C$ shows the mean + SEM levels of freezing to S2 and S1 (left panels) across second-order conditioning. No significant difference in freezing to S2 or S1 was found between groups across second-order conditioning $\left(F_{(1,27)}<1\right.$; $p>0.05)$. A nonsignificant linear $\times$ group interaction confirmed that the rate of acquisition of second-order fear did not differ between groups $\left(F_{(1,27)}<1 ; p>0.05\right)$. Figure $4 C$ (third panel) shows mean + SEM levels of freezing across S2 extinction. Ifenprodil did not disrupt within-session extinction learning. Levels of freezing between ifenprodil- and vehicle-treated rats did not differ $\left(F_{(1,27)}<1 ; p>0.05\right)$. A nonsignificant linear $\times$ group interaction confirmed that the rate of extinction did not differ between groups $\left(F_{(1,27)}<1.4 ; p>0.05\right)$. The right panel of Figure $4 C$ shows mean + SEM levels of freezing to S2 across testing. Ifenprodil impaired long-term extinction of S2. Rats receiving S2 extinction under ifenprodil froze more on test than vehicletreated rats $\left(F_{(1,27)}=7.29 ; p<0.05\right)$. Infusion of ifenprodil across $\mathrm{S} 2$ extinction did not affect the first-order fear memory. Levels of freezing to $\mathrm{S} 1$ at test did not differ between groups 
$\left(F_{(1,27)}<1 ; p>0.05\right)$. This was confirmed by a nonsignificant linear $X$ group interaction $\left(F_{(1,27)}<1 ; p>0.05\right)$.

\section{Experiment 4: Acquisition of sensory preconditioned fear responses to $\mathrm{S} 2$ is contingent on its pairings with $\mathrm{S} 1$ and on subsequent pairings of $S 1$ and the US}

The aim of this experiment was to confirm that sensory preconditioning to S2 was contingent on its pairings with $\mathrm{S} 1$ and on subsequent pairings of $\mathrm{S} 1$ and the US. Three groups of rats were used $[n=7$ (PP), 8 (PU), and 8 (UP)]. On the first $2 \mathrm{~d}$, groups received preexposure to the conditioning context. On day 3, rats received paired (groups PP and $\mathrm{PU}$ ) or unpaired (group UP) sensory preconditioning. On days $4-5$, rats received paired (groups PP and UP) or unpaired (group PU) first-order conditioning. On day 6, all groups received a context extinction session. Rats were placed into the conditioning context for $30 \mathrm{~min}$ and then returned to the home cages. Four hours later, rats were returned to the conditioning chambers and were tested for fear of S2. Rats were tested for fear of S1 on day 7.

\section{Behavior}

Levels of freezing during the $30 \mathrm{~s}$ period before the first stimulus onset were $<15 \%$ across all phases of the experiment and did not differ significantly between groups $\left(F_{(1,20)}<1 ; p>0.05\right)$. No groups showed substantial freezing to the stimuli across sensory preconditioning trials, indicating that neither stimulus was innately aversive ( $<15 \%$ freezing across the session). First-order conditioning was successful. On the final trial of conditioning, levels of freezing to S1 were significantly greater for groups receiving paired first-order conditioning (groups PP and UP) than for the group receiving unpaired conditioning (group PU; $\left.F_{(1,20)}=109.81 ; p<0.05\right)$. Levels of freezing on the final trial did not differ between groups PP and UP $\left(F_{(1,20)}<2.8 ; p>0.05\right)$. The left panel of Figure 5 shows mean + SEM levels of freezing to S2 across testing. Levels of freezing to S2 were significantly higher in rats receiving both paired sensory preconditioning and firstorder conditioning (group PP) than rats in unpaired groups $\mathrm{PU}$ and $\operatorname{UP}\left(F_{(1,20)}=18.94 ; p<0.05\right)$. A significant linear $\times$ group interaction confirmed that the decline in freezing to S2 was greater for group PP than for unpaired groups $\left(F_{(1,20)}=14.00\right.$; $p<0.05)$. Levels of freezing to S2 did not differ significantly between the unpaired control groups, $\mathrm{PU}$ and $\mathrm{UP}\left(F_{(1,20)}<1 ; p>\right.$ $0.05)$. This was confirmed by a nonsignificant linear $\times$ group interaction $\left(F_{(1,20)}<1 ; p>0.05\right)$. Rats receiving paired firstorder trials across conditioning (groups PP and UP) showed significantly more freezing to $\mathrm{S} 1$ at test than rats receiving unpaired first-order conditioning trials (group PU) $\left(F_{(1,20)}=\right.$ $65.39 ; p<0.05)$. Levels of freezing to $S 1$ did not differ significantly between groups PP and UP $\left(F_{(1,20)}<1 ; p>0.05\right)$. This was confirmed by a nonsignificant linear $\times$ group interaction $\left(F_{(1,20)}<1 ; p>0.05\right)$.

\section{Experiment 5: Acquisition of sensory preconditioned fear does not require the BLA but does require activation of NMDA receptors}

In this experiment, we examined the effect of BLA infusion of the $\mathrm{GABA}_{\mathrm{A}}$ receptor agonist muscimol (group MUS) and systemic administration of the NMDAr antagonist MK-801 (group MK-
801) on the acquisition of sensory preconditioned fear. These experiments were run consecutively. On the first $2 \mathrm{~d}$, rats were preexposed to the conditioning context. On day 3, rats were infused/injected with either drug or vehicle and then received paired sensory preconditioning. On day 4, all rats received paired first-order conditioning and on day 5 received context extinction. Rats were placed into the conditioning context for $30 \mathrm{~min}$ and then returned to the home cages. Four hours later, rats were returned to the conditioning chambers and were tested for fear of S2. Rats were tested for fear of S1 on day 6.

\section{Histology}

Figure $2 C$ shows the approximate location of injection cannula tips. The plotted points represent the ventral point of the cannula track. A total of four rats were excluded because of incorrect placement or damage. This yielded the following group sizes: group MUS, $n=10$; group VEH (muscimol control), $n=10$; group MK-801, $n=12$; and group VEH (MK-801 control), $n=11$.

\section{Behavior}

$B L A$ infusion of $G A B A_{A}$ receptor agonist muscimol. Levels of freezing during the $30 \mathrm{~s}$ period before the first stimulus onset $<20 \%$ across all phases of the experiment and did not differ significantly between groups $\left(F_{(1,18)}<1 ; p>0.05\right)$. Both groups showed low levels of freezing to the stimuli across sensory preconditioning trials, indicating that neither stimulus was innately aversive $(<15 \%$ across the session). First-order conditioning was successful. Infusion of muscimol before sensory preconditioning trials had no effect of the subsequent acquisition of first-order fear because levels of freezing to S1 did not differ between groups $\left(F_{(1,18)}<1 ; p>0.05\right)$. A nonsignificant linear $\times$ group interaction confirmed that the rate of acquisition of first-order fear did not differ between groups $\left(F_{(1,18)}<1 ; p>0.05\right)$. The middle panel of Figure 5 shows the mean + SEM levels of freezing to S2 across testing. BLA activation is not necessary for the acquisition of sensory preconditioned fear. Levels of freezing to S2 did not differ between muscimol- and vehicle-treated rats $\left(F_{(1,18)}<1 ; p>0.05\right)$. This was confirmed by a nonsignificant linear $\times$ group interaction $\left(F_{(1,18)}<1 ; p>0.05\right)$. Infusion of muscimol before sensory preconditioning left the first-order fear memory intact. Levels of freezing to $S 1$ at test did not differ between groups $\left(F_{(1,18)}<1 ; p>0.05\right)$. This was also confirmed by a nonsignificant linear $\times$ group interaction $\left(F_{(1,18)}<1 ; p>0.05\right)$.

Systemic administration of the NMDAr antagonist MK-801. Levels of freezing during the $30 \mathrm{~s}$ period before the first stimulus onset were $<15 \%$ across all phases of the experiment and did not differ significantly between groups $\left(F_{(1,21)}<1 ; p>0.05\right)$. Neither 
group showed substantial freezing to the stimuli across sensory preconditioning trials, indicating that neither stimulus was innately aversive ( $<15 \%$ across the session). First-order conditioning was successful. Injection of MK-801 before sensory preconditioning had no effect on the subsequent acquisition of first-order fear because levels of freezing to S1 did not differ between groups. A nonsignificant linear $\times$ group interaction confirmed that the rate of acquisition did not differ between the groups $\left(F_{(1,21)}<2 ; p>0.05\right)$. The right panel of Figure 5 shows the mean + SEM levels of freezing to S2 across testing. NMDAr activation is necessary for the acquisition of second-order conditioned fear. Vehicle-treated rats froze more to S2 than MK-801treated rats $\left(F_{(1,21)}=4.43 ; p<0.05\right)$, averaged across the first five trials only. Injection of MK-801 before sensory preconditioning had no affect on the first-order fear memory. Levels of freezing to $\mathrm{S} 1$ at test did not differ between groups $\left(F_{(1,21)}<1 ; p>0.05\right)$. This was confirmed by a nonsignificant linear $\times$ group interaction $\left(F_{(1,21)}<1 ; p>0.05\right)$.

Experiment 6: Preextinction of the S2-S1 association does not require the BLA but does require NMDAr activation

In this study, we examined the effect of BLA infusion of the $\mathrm{GABA}_{\mathrm{A}}$ receptor agonist muscimol (group MUS) and systemic administration of the NMDAr antagonist MK-801 (group MK801) on preextinction of sensory preconditioning. Preextinction refers to the extinction of the S2-S1 association before firstorder conditioning (Coppock, 1958). These experiments were run simultaneously. On the first $2 \mathrm{~d}$, rats were preexposed to the conditioning context and on day 3 received paired sensory preconditioning. On day 4, rats were infused/injected with drug or vehicle then received S2 extinction training. Group NO_EXT received an equal amount of control exposure to the context only under drug or vehicle. On day 5, all rats received paired firstorder conditioning. Rats were tested for fear of S2 and S1 on days 6 and 7, respectively.

\section{Histology}

Figure $2 D$ shows the approximate location of injection cannula tips. The plotted points represent the ventral point of the cannula track. No rats were excluded yielded the following group sizes: group MUS, $n=8$; group MK-801, $n=12$; group VEH, $n=21$; and group NO_EXT, $n=12$.

\section{Behavior}

Levels of freezing during the $30 \mathrm{~s}$ period before the first stimulus onset were $<20 \%$ across all phases of the experiment and did not differ significantly between groups $\left(F_{(1,49)}<1 ; p>0.05\right)$. No groups showed substantial freezing to the stimuli across sensory preconditioning trials, indicating that neither stimulus was innately aversive ( $<15 \%$ across the session). First-order conditioning was successful. No significant difference in freezing to $S 1$ was found between groups across first-order training $\left(F_{(1,49)}<1 ; p>\right.$ $0.05)$. Nonsignificant linear $\times$ group interactions confirmed that the rate of acquisition of fear to S1 did not differ between groups $\left(F_{(1,49)}<1 ; p>0.05\right)$. Groups MUS, MK-801, and VEH showed $<20 \%$ freezing across S2 extinction and levels of freezing did not differ between these groups $\left(F_{(1,49)}<1 ; p>\right.$ $0.05)$. Figure 6 shows mean + SEM levels of freezing to S2 across testing. The preextinction of sensory conditioning does not require BLA activation but does require NMDAr activation. Muscimol- and vehicle-treated rats froze less to S2 than MK-801-treated and nonextinguished rats $\left(F_{(1,49)}=14.26\right.$; $p<0.05)$. Levels of freezing to S2 did not differ between

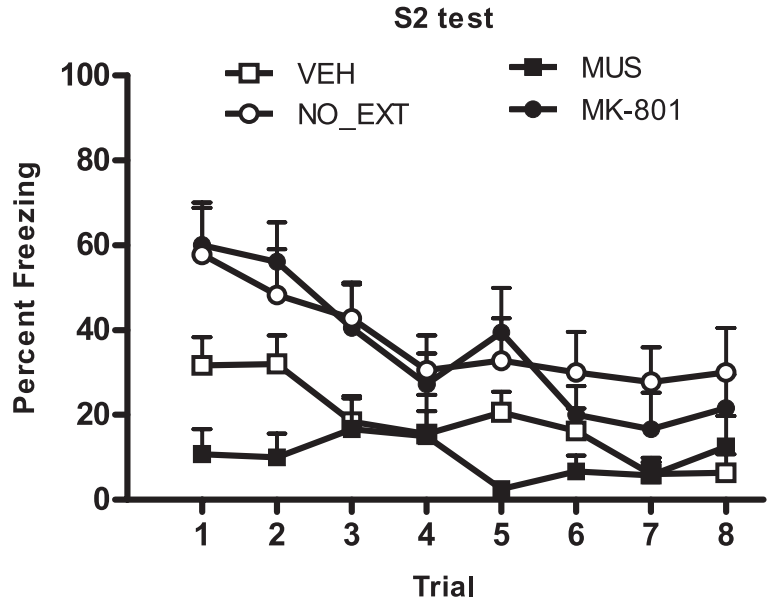

Figure 6. Preextinction of the $S 2-S 1$ association does not require the $B L A$ but does require NMDAr activation (experiment 6). Mean + SEM levels of freezing at $\$ 2$ test for muscimol (filled squares), MK-801 (filled circles), vehicle (open squares), and nonextinguished (open circles) rats.

muscimol and vehicle rats $\left(F_{(1,49)}<1 ; p>0.05\right)$ nor between MK-801 and nonextinguished rats $\left(F_{(1,49)}<1 ; p>0.05\right)$. Preextinction of the S2-S1 association under muscimol, MK801 , and vehicle left the first-order fear memory intact. Levels of freezing to $S 1$ at test did not differ between groups $\left(F_{(1,49)}<\right.$ $1 ; p>0.05)$. This was confirmed by nonsignificant linear $\times$ group interactions $\left(F_{(1,49)}<1 ; p>0.05\right)$.

\section{Experiment 7: Extinction of sensory preconditioned fear requires the BLA, NMDAr, and NR2B subunit activation in the BLA}

In this experiment, we investigated the effect of BLA infusion of the $\mathrm{GABA}_{\mathrm{A}}$ receptor agonist muscimol (group MUS), systemic administration of the NMDAr antagonist MK-801 (group MK801), and BLA infusion of the NMDAr NR2B subunit-selective antagonist ifenprodil (group IFEN) on extinction of sensory preconditioned fear. These experiments were run simultaneously. On the first $2 \mathrm{~d}$, rats were preexposed to the conditioning context and on day 3 received paired sensory preconditioning. On day 4 , rats received paired first-order conditioning. On day 5 , rats were infused/injected with drug or vehicle and then received S2 extinction training. Rats in group NO_EXT received control exposure to the context only under drug or vehicle. Rats were tested for fear of S2 and S1 on days 6 and 7, respectively.

\section{Histology}

Figure $2 D$ shows the approximate location of injection cannula tips. The plotted points represent the ventral point of the cannula track. A total of nine rats were excluded because of incorrect placement or damage. This yielded the following group sizes: group MUS, $n=8$; group MK-801, $n=8$; group IFEN, $n=8$, group VEH, $n=7$; and group NO_EXT, $n=8$.

\section{Behavior}

Levels of freezing during the $30 \mathrm{~s}$ period before the first stimulus onset were $<20 \%$ across all phases of the experiment and did not differ significantly between groups $\left(F_{(1,34)}<1 ; p>0.05\right)$. No groups showed substantial freezing to the stimuli across sensory preconditioning trials, indicating that neither stimulus was innately aversive ( $<15 \%$ across the session). First-order conditioning was successful. No significant difference in freezing to $S 1$ was found between groups across first-order training $\left(F_{(1,34)}<1 ; p>\right.$ 


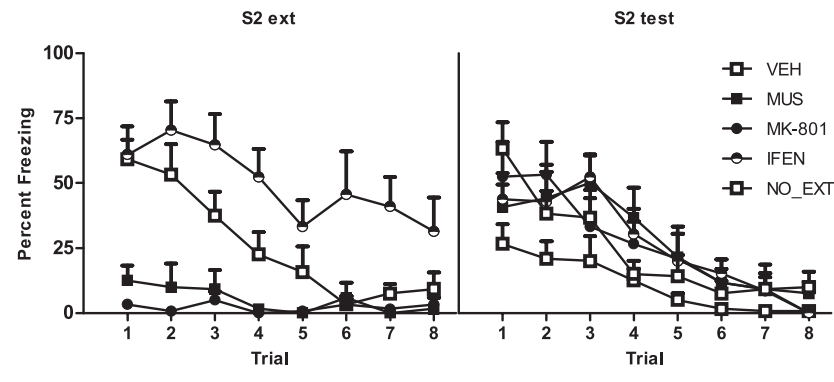

Figure 7. Extinction of sensory preconditioned fear requires the BLA, NMDAr, and $\mathrm{NR2Br}$ activation in the BLA (experiment 7). Mean + SEM levels of freezing across S2 extinction (left panel) and at $\$ 2$ test (right panel) for muscimol (filled squares), MK-801 (filled circles), ifenprodil (open/filled circles), vehicle (open squares), and nonextinguished (open circles) rats.

0.05). No significant linear $\times$ group interactions were found, confirming that the rate of acquisition of fear to $\mathrm{S} 1$ did not differ between groups $\left(F_{(1,34)}<1 ; p>0.05\right)$. The left panel of Figure 7 shows mean + SEM levels of freezing across S2 extinction. Ifenprodil impaired within session extinction training. Group IFEN froze more to $\mathrm{S} 2$ across extinction than the remaining groups $\left(F_{(1,27)}=41.47 ; p<0.05\right)$. MK-801 and muscimol depressed the freezing response. Vehicle-treated rats froze more to $\mathrm{S} 2$ than rats receiving MK-801 or muscimol $\left(F_{(1,27)}=24.46 ; p<0.05\right)$. Levels of freezing did not differ between MK-801- and muscimoltreated rats $\left(F_{(1,34)}<1.6 ; p>0.05\right)$.

The right panel of Figure 7 shows mean + SEM levels of freezing to S2 across testing. Extinction of sensory preconditioned fear requires the BLA, NMDAr, and NR2Br activation in the BLA. All drug-treated rats (groups MUS, MK-801, and IFEN) froze more to $\mathrm{S} 2$ than vehicle-treated rats $\left(F_{(1,34)}=9.08 ; p<\right.$ $0.05)$. Levels of freezing did not differ between all drug-treated rats and nonextinguished controls $\left(F_{(1,34)}<1 ; p<0.05\right)$. Rats receiving a systemic injection of $\mathrm{MK}-801$ did not differ significantly from rats receiving BLA infusions of muscimol or ifenprodil $\left(F_{(1,34)}<1 ; p>0.05\right)$, nor did muscimol- and ifenprodil-treated rats differ significantly from each other $\left(F_{(1,34)}<1 ; p<0.05\right)$. Injection of MK-801 or infusion of muscimol or ifenprodil across S2 extinction did not affect the first-order fear memory. Levels of freezing to $\mathrm{S} 1$ at test did not differ between groups $\left(F_{(1,34)}<1\right.$; $p<0.05)$. This was confirmed by nonsignificant linear $\times$ group interactions $\left(F_{(1,34)}<4\right.$; $\left.p<0.05\right)$.

\section{Discussion}

The present experiments confirmed that rats learn to fear stimuli that signal a learned source of danger. In experiment 1, rats exposed to S1-US pairings subsequently froze to S2 across its pairings with the conditioned S1. In contrast, rats that received S1-US pairings but not S2-S1 pairings or rats that received S2-S1 pairings but not the previous S1-US pairings failed to develop such fear responses. Thus, second-order conditioned fear to S2 was attributable to its association with $\mathrm{S} 1$, rather than to generalization of fear from $S 1$ and to $S 1$ having been conditioned by the US, rather than to innate conditioning properties of S1. The maintenance of fear to S2 was contingent on its continued pairings with S1 because fear extinguished when S2 was repeatedly exposed in the absence of S1 (experiment 3). In experiment 4, rats exposed to S2-S1 pairings followed by S1-US pairings froze when tested with S2. This sensory preconditioned fear was attributable to the association between S2 and $\mathrm{S} 1$, rather than to generalization of fear from S1 or to innate conditioning properties of S1. Fear of S2 depended on an intact association with S1. S2 alone exposures after the S2-S1 pairings but before S1-US pairings eliminated fear of S2 (experiment 6) and S2 alone exposure after S1-US pairings extinguished fear of S2 (experiment 7).

The substrates underlying the acquisition of second-order fear are those known to mediate acquisition of first-order fear. Each is impaired by BLA infusion of muscimol, systemic administration of MK-801, and BLA infusion of ifenprodil. There is considerable evidence that the S1-US association requires NMDAr activation in the BLA to initiate the molecular changes that stabilize the long-term fear memory. Long-term potentiation (LTP) shares molecular mechanisms with fear conditioning (Tsien, 2000; Kim and Jung, 2006). Blockade of NMDAr prevents the induction of LTP in the BLA and the acquisition of first-order fear responses (Rodrigues et al., 2001). LTP is induced in the BLA through the concurrent activation of CS and US inputs, which causes glutamate release and postsynaptic depolarization, leading to NMDAr activation and calcium entry into the postsynaptic neuron. The calcium entry activates the transduction cascade necessary for LTP and, coupled with intact protein synthesis, leads to the formation of the long-term fear memory. This strengthening of synaptic transmission enables the CS to excite BLA neurons that project to fear-output neurons in central nucleus of the amygdala (CeA) (Malenka and Nicoll, 1999). Likewise, concurrent activation of S2 and S1 inputs across their pairings may cause glutamate release and postsynaptic depolarization, leading to changes in the synaptic efficiency such that S2 comes to excite the BLA projection neurons to the CeA whose outputs control the fear response.

The substrates underlying extinction of both second-order and sensory preconditioned fear are those known to underlie extinction of first-order conditioned fear. The long-term fear inhibition produced by extinction of each of these fears is disrupted by BLA infusion of muscimol (Herry et al., 2008), systemic administration of MK-801 (Chan and McNally, 2009), and BLA infusion of ifenprodil (Rodrigues et al., 2001). The neural circuitry underling first-order fear inhibition involves interactions among several structures, including the BLA and the infralimbic (IL) subregion of the medial prefrontal cortex. Specifically, the IL appears necessary for the consolidation and retrieval of first-order fear extinction but not its acquisition (Laurent and Westbrook, 2009; Sotres-Bayon et al., 2009). The IL is likely to suppress fear responses via excitatory projections to "extinction" neurons in the BLA (Herry et al., 2008) and to a network of inhibitory interneurons (intercalated neurons) located between the BLA and CeA (Paré and Smith, 1993; Quirk and Mueller, 2008). Extinction of second-order and sensory preconditioned fear may also recruit this circuitry, but the roles of the IL and extinction neurons in mediating inhibition of such fear remains to be determined.

Just as NMDAr activation is required for the acquisition of first- and second-order conditioned fear, activation of these receptors is required for the $\mathrm{S} 2-\mathrm{S} 1$ association in sensory preconditioning. Rats injected with MK-801 before S2-S1 pairings failed to show fear when tested with S2. Just as NMDAr activation is required for extinction of sensory preconditioned, second- and first-order fear, these receptors are also critical for extinction of the S2-S1 association. Rats that received S2 alone exposures between S2-S1 pairings and S1-US pairings failed to show fear when tested with S2 but rats that received these exposures under MK-801 continued to show that fear, indicating that the S2-S1 association remained intact.

However, in contrast to the role played by the BLA in the acquisition of first- and second-order conditioned fear, the formation of associations between two neutral stimuli is indepen- 
dent of the BLA. Moreover, again in contrast to the role of the BLA in the extinction of first-order, second-order, and sensory preconditioned fear, extinction of the association between two neutral stimuli is also independent of the BLA. Rats infused with muscimol into the BLA before the S2-S1 pairings exhibited normal sensory preconditioned fear of S2 and rats infused with muscimol into the BLA before the S2 alone exposures exhibited the normal absence of fear. The ability of rats to form an S2-S1 association despite a muscimol infusion into the BLA is consistent with a previous report that rats with lesions of the BLA acquired within-event, flavor-flavor associations. Dwyer and Killcross (2006) exposed thirsty rats to two solutions, each of which contained two flavors (AX and BY), made the rats sick after ingestion of $\mathrm{X}$ but not $\mathrm{Y}$ and then tested the rats for intake of $\mathrm{A}$ versus $B$. They found that lesioned rats avoided $A$, the associate of the poisoned X, just as much as control rats. The present results suggest that extinction of the AX association by A alone exposures before pairings of $\mathrm{X}$ and illness would have eliminated avoidance of $\mathrm{A}$ and that lesioned rats would have shown just as little avoidance of $\mathrm{A}$ as control rats.

Rescorla and colleagues (Rizley and Rescorla, 1972; Rescorla, 1973, 1979) reported that extinction of S1 (the first-order CS) eliminated sensory preconditioned but spared second-order fear responses to S2. These results suggest that sensory preconditioned fear is mediated by the association between the sensory properties of S2 and S1, because S2 fails to elicit fear when its S1 associate is no longer frightening. In contrast, second-order fear is primarily mediated by the association formed between $\mathrm{S} 2$ and the fear elicited by S1, because most evidence shows that S2 elicits fear even when S1 is no longer frightening (Gewirtz and Davis, 2000), especially when S2 and S1 are from different modalities as in the present experiments (Rescorla, 1980). According to these results, the muscimol infusion into the BLA before second-order conditioning depressed the fear responses elicited by S1 and thereby undermined the formation of the association between S2 and the fear responses, which underlies second-order conditioning. However, the sensory preconditioned data show that the S2-S1 (stimulus-stimulus) association does not require the BLA. Hence, that association should have been formed across the second-order pairings, resulting in essentially sensory preconditioned fear on the subsequent test of S2. However, this did not occur. Together, these various results suggest that the brain regions that mediate the association between two neutral stimuli, S2 and S1 (1) are not activated when the BLA is recruited to form an association between a neutral stimulus (S2) and the fear elicited by S1 and (2) cannot compensate when neuronal activity in the BLA is disrupted across second-order pairings (experiment 2).

The brain regions involved in encoding the association between the neutral S2 and S1 remain to be determined. Early studies identified an involvement of the hippocampus (Port and Patterson, 1984; Port et al., 1987). However, more selective lesions, which leave parahippocampal regions intact, do not impair sensory preconditioning (Ward-Robinson et al., 2001). Moreover, Nicholson and Freeman (2000) have shown that rats with lesions of the perirhinal cortex (PRh) acquired normal protective reflexes to $S 1$ paired with periorbital shock but failed to show sensory preconditioned reflexes to S2. Because such reflexes constitute a component of the fear system, it seems likely that the PRh would also underlie the S2-S1 associations formed in the present experiments. The reciprocal connections between the PRh (areas 35 and 36) and the lateral and basal nuclei of the amygdala (Pitkänen et al., 2000) are consistent with such a suggestion.

In summary, we have shown that BLA NMDAr activity is necessary for the acquisition and extinction of second-order conditioned fear. The acquisition and preextinction of sensory preconditioning requires NMDAr activity but not BLA activation. However, once the fear circuit is engaged, learning to inhibit sensory preconditioned fear becomes BLA NMDAr dependent. These findings are consistent with current views of amygdala function (Maren, 2003). We have suggested that first- and second-order fear acquisition and extinction are governed by the same neural substrates, and, hence, current treatments for anxiety disorders based on NMDAr function in first-order fear extinction will also be effective in facilitating the inhibition of second-order fear associations present in these disorders.

\section{References}

Bauer EP, Schafe GE, LeDoux JE (2002) NMDA receptors and L-type voltage-gated calcium channels contribute to long-term potentiation and different components of fear memory formation in the lateral amygdala. J Neurosci 22:5239-5249.

Chan WY, McNally GP (2009) Conditioned stimulus familiarity determines effects of MK-01 on fear extinction. Behav Neurosci 123:303-314.

Coppock WJ (1958) Pre-extinction in sensory preconditioning. J Exp Psychol 55:213-219.

Debiec J, Doyère V, Nader K, Ledoux JE (2006) Directly reactivated, but not indirectly reactivated, memories undergo reconsolidation in the amygdala. Proc Natl Acad Sci U S A 103:3428-3433.

Dwyer DM, Killcross S (2006) Lesions of the basolateral amygdala disrupt conditioning based on the retrieved representations of motivationally significant events. J Neurosci 26:8305-8309.

Fanselow MS (1980) Conditional and unconditional components of postshock freezing. Pavlov J Biol Sci 15:177-182.

Gewirtz JC, Davis M (1997) Second-order fear conditioning prevented by blocking NMDA receptors in amygdala. Nature 388:471-474.

Gewirtz JC, Davis M (2000) Using pavlovian higher-order conditioning paradigms to investigate the neural substrates of emotional learning and memory. Learn Mem 7:257-266.

Hays, WL (1963) Statistics for psychologists. New York: Holt, Rinehart and Winston.

Herry C, Ciocchi S, Senn V, Demmou L, Müller C, Lüthi A (2008) Switching on and off fear by distinct neural circuits. Nature 454:600-606.

Kim JJ, Jung MW (2006) Neural circuits and mechanisms involved in Pavlovian fear conditioning: a critical review. Neurosci Biobehav Rev 30:188-202.

Laurent V, Westbrook RF (2009) Inactivation of the infralimbic but not the prelimbic cortex impairs consolidation and retrieval of fear extinction. Learn Mem 16:520-529.

Malenka RC, Nicoll RA (1999) Long-term potentiation: a decade of progress? Science 285:1870-1874.

Maren S (2003) The amygdala, synaptic plasticity and fear memory. Ann N Y Acad Sci 985:106-113.

Nader K, LeDoux JE (1999) Inhibition of the mesoamygdala dopaminergic pathway impairs the retrieval of conditioned fear associations. Behav Neurosci 113:891-901.

Nicholson DA, Freeman JH Jr (2000) Lesions of the perirhinal cortex impair sensory preconditioning in rats. Behav Brain Res 112:69-75.

Paré D, Smith Y (1993) The intercalated cell masses project to the central and medial nuclei of the amygdala in cats. Neuroscience 57:1061-1076.

Paxinos G, Watson C (1997) The rat brain in stereotaxic coordinates, Ed 3. San Diego: Academic.

Pitkänen A, Pikkarainen M, Nurminen N, Ylinen A (2000) Reciprocal connections between the amygdala and the hippocampal formation, perirhinal cortex, and postrhinal cortex in rat: a review. Ann N Y Acad Sci 911:369-391.

Port RL, Patterson MM (1984) Fimbrial lesions and sensory preconditioning. Behav Neurosci 98:584-589.

Port RL, Beggs AL, Patterson MM (1987) Hippocampal substrate of sensory associations. Physiol Behav 39:643-647. 
Quirk GJ, Mueller D (2008) Neural mechanisms of extinction learning and retrieval. Neuropsychopharmacology 33:56-72.

Rescorla RA (1973) Effect of US habituation following conditioning. J Comp Physiol Psychol 82:137-143.

Rescorla RA (1979) Aspects of the reinforcer learned in second-order Pavlovian conditioning. J Exp Psychol Anim Behav Process 5:79-95.

Rescorla RA (1980) Pavlovian second-order conditioning: studies in associative learning. New Jersey: Erlbaum.

Rizley RC, Rescorla RA (1972) Associations in second-order conditioning and sensory preconditioning. J Comp Physiol Psychol 81:1-11.

Rodrigues SM, Schafe GE, LeDoux JE (2001) Intra-amygdala blockade of the NR2B subunit of the NMDA receptor disrupts the acquisition but not the expression of fear conditioning. J Neurosci 21:6889-6896.

Sotres-Bayon F, Bush DE, LeDoux JE (2007) Acquisition of fear extinction requires activation of NR2B-containing NMDA receptors in the lateral amygdala. Neuropsychopharmacology 32:1929-1940.

Sotres-Bayon F, Diaz-Mataix L, Bush DE, LeDoux JE (2009) Dissociable roles for the ventromedial prefrontal cortex and amygdala in fear extinction: NR2B contribution. Cereb Cortex 19:474-482.

Tsien JZ (2000) Linking Hebb's coincidence-detection to memory formation. Curr Opin Neurobiol 10:266-273.

Ward-Robinson J, Coutureau E, Good M, Honey RC, Killcross AS, Oswald CJ (2001) Excitotoxic lesions of the hippocampus leave sensory preconditioning intact: implications for models of hippocampal function. Behav Neurosci 115:1357-1362.

Wilensky AE, Schafe GE, LeDoux JE (1999) Functional inactivation of the amygdala before but not after auditory fear conditioning prevents memory formation. J Neurosci 19:RC48(1-5). 